\title{
Measuring students' approaches to learning in different clinical rotations
}

\author{
Ova Emilia ${ }^{*}$, Leah Bloomfield ${ }^{2}$ and Arie Rotem ${ }^{2}$
}

\begin{abstract}
Background: Many studies have explored approaches to learning in medical school, mostly in the classroom setting. In the clinical setting, students face different conditions that may affect their learning. Understanding students' approaches to learning is important to improve learning in the clinical setting. The aim of this study was to evaluate the Study Process Questionnaire (SPQ) as an instrument for measuring clinical learning in medical education and also to show whether learning approaches vary between rotations.
\end{abstract}

Methods: All students involved in this survey were undergraduates in their clinical phase. The SPQ was adapted to the clinical setting and was distributed in the last week of the clerkship rotation. A longitudinal study was also conducted to explore changes in learning approaches.

Results: Two hundred and nine students participated in this study (response rate 82.0\%). The SPQ findings supported a two-factor solution involving deep and surface approaches. These two factors accounted for $45.1 \%$ and $22.5 \%$, respectively, of the variance. The relationships between the two scales and their subscales showed the internal consistency and factorial validity of the SPQ to be comparable with previous studies. The clinical students in this study had higher scores for deep learning. The small longitudinal study showed small changes of approaches to learning with different rotation placement but not statistically significant.

Conclusions: The SPQ was found to be a valid instrument for measuring approaches to learning among clinical students. More students used a deep approach than a surface approach. Changes of approach not clearly occurred with different clinical rotations.

Keywords: Approaches to learning, Study Process Questionnaire (SPQ), Learning process, Clinical teaching

\section{Background}

The concept of approach to learning has been studied extensively because it is strongly related to students' level of understanding and learning outcomes. In general, three different approaches have been described: deep, surface and strategic [1-3]. Students who adopt a deep approach are predominantly motivated by an interest in learning for its own sake and an interest in the subject material. They attempt to understand the underlying structure and meaning, examine evidence critically, use it cautiously and actively relate new information to previous knowledge. Students who adopt a surface approach are predominantly motivated either by a desire simply to complete the course or by a fear of failure.

\footnotetext{
*Correspondence: ovaemilia@yahoo.com.au

'Faculty of Medicine, Universitas Gadjah Mada, Jl. Farmako, Sekip Utara, Yogyakarta, Indonesia

Full list of author information is available at the end of the article
}

Their intention is to fulfill the course requirements by memorizing and reproducing specific facts or pieces of disconnected information for examinations. They tend to be anxiously aware of assessment requirements and prefer to restrict learning to a defined syllabus and specified tasks. Students who adopt a strategic/achieving approach are predominantly motivated by the achievement of high grades and a sense of competition. Their main intention is to be successful, and they are prepared to use any means necessary, depending on what they feel would produce the most successful results.

Several instruments have been developed to measure the behavioral and conceptual processes in which students engage while learning. These include the Inventory of Learning Processes, the Approaches to Studying Inventory and the Study Process Questionnaire (SPQ) [4]. This study focused on the SPQ.




The SPQ was developed from the earlier 10-scale Study Behaviour Questionnaire (SBQ), which was conceived within an information-processing framework. The SBQ initially contained 72 items, but was later extended to 80 items covering 10 subscales. In the subsequent SPQ, some of the items in the SBQ were reclassified and the 10 subscales were relabeled [1]. It was demonstrated that these relabeled subscales could be subsumed under three second-order factors interpreted as the reproducing, internalizing and organizing dimensions of students' learning. Although these were intended to encompass the values, motives and cognitive strategies associated with particular aspects of learning, they are broadly comparable with the surface, deep and strategic approaches that had been defined earlier. Ultimately, Biggs [5] reduced the SPQ to seven items in each of six subscales reflecting the respondents' motives and strategies within each of the three major dimensions, and renamed them as surface, deep and achieving approaches to learning to bring the terminology into line with that of other researchers (Table 1).

In 1992, Biggs [5] summarized work with the 3P (presage, process, product) model using the SPQ, focusing on students' motives and strategies for learning. These motives and strategies have been examined in various contexts, including cross-cultural comparisons, the language medium of instruction, teaching and learning environments, professional and staff development, and factor structure and the dimensionality of subscales [6-8].

When using the SPQ to monitor teaching/learning environments, the role of the scales related to achieving is not as evident as that of the deep and surface scales. Indeed, the achieving motive and strategy differ from the deep and surface motives and strategies from the outset [5]. Whereas deep and surface strategies describe the way students engage in a task, the achieving strategy refers to how the student organizes when and where the task will be engaged, and for how long. Factor analyses usually associate the achieving motive and strategy with the deep approach, but depending on the subject and teaching conditions, achieving-related scores sometimes have a bearing on the surface approach. Using confirmatory factor analysis, the SPQ is most conveniently described in terms of two factors - deep and surface -

Table 1 Three prototypical approaches to learning

\begin{tabular}{lll}
\hline Approach & Motive & Strategy \\
\hline Surface & $\begin{array}{l}\text { Extrinsic: avoid failure } \\
\text { but don't work too hard }\end{array}$ & $\begin{array}{l}\text { Focus on selected details and } \\
\text { reproduce accurately }\end{array}$ \\
\hline Deep & $\begin{array}{l}\text { Intrinsic: satisfy curiosity } \\
\text { about topic }\end{array}$ & $\begin{array}{l}\text { Maximize understanding: read } \\
\text { widely, discuss, reflect }\end{array}$ \\
\hline Achieving & $\begin{array}{l}\text { Achievement: compete } \\
\text { for highest grade }\end{array}$ & $\begin{array}{l}\text { Optimize organization of time } \\
\text { and effort (study skills) }\end{array}$ \\
\hline
\end{tabular}

with achieving motive and strategy subscales aligned with both of these factors $[7,9]$.

Responding to the need for a shorter, two-factor version of the SPQ that addresses deep and surface approaches only and can be administered quickly and easily by a regular teacher, Biggs and colleagues [10] developed a simple version comprising two factors (deep and surface) with 20 items. This version of the questionnaire has acceptable Cronbach's alpha reliability values (0.64 for surface approach and 0.73 for deep approach).

Concerning medical students' approaches to learning, studies have used several different instruments: Biggs's SPQ, obtaining scores for surface, deep and achieving learning approaches; the Entwistle-Ramsden Lancaster Approaches to Studying Inventory, obtaining scores for reproducing, meaning and achieving orientations to learning; the Schmeck Inventory of Learning Process; and the Adelaide Diagnostic Learning Inventory for Medical Students [1-3,11-14].

These earlier studies investigated approaches to learning in the classroom setting. However, learning in the clinical setting during medical education is a different environment, and differences in learning are associated with department-related and student-related factors (one being the approach to learning) and interactions between them. Understanding the student factor is important in improving learning in the clinical setting [15-17]. In a recent qualitative study in a clinical learning context, three factors affecting students' learning approaches were identified: clinical supervisors and supervision, stress and anxiety, and assessment [18]. The purpose of the present study was to assess the reliability and validity of the SPQ for use in clinical learning in medical education and also to determine whether learning approaches vary between rotations.

\section{Methods \\ Participants}

A cross-sectional quantitative study was conducted among students in years 5 and 6 who were undertaking clerkships at the Faculty of Medicine, Universitas Gadjah Mada, Indonesia. The clerkships comprise several rotations of varying length that all students should follow completely. For the study, the inclusion criterion was undergraduate medical students who were undertaking a clinical clerkship during the data collection period. Students in community medicine or public health rotations who were working outside the hospital setting were excluded.

The SPQ questionnaire had already been modified for the clinical context and was distributed to 255 students in the last week of their clerkship rotation. The students were asked to complete the questionnaire related to their current rotation and return it at the end of the week to their student coordinator, who then sent the questionnaires 
to the researcher. Only students who returned a completed questionnaire were included in the analysis.

A sample of students was selected to participate in a more extensive longitudinal study to explore changes in approaches to learning in three different rotations over a period of 30 weeks. Random sampling was not feasible. Thus, group randomization representing different rotations was used. This resulted in three groups from internal medicine, surgery and neurology that comprised 39 students. For this longitudinal study, a questionnaire survey after each rotation was conducted, and focus group discussions were held at the end of the three rotations.

\section{The instrument}

The SPQ was selected from various instruments that measure students' learning approaches. According to Biggs, a student's learning approach is a function of both a motive and a strategy [1], with the motive influencing the learning and studying strategies that the student adopts. Although Biggs claimed that students' approaches are relatively stable over time, several studies have demonstrated the contextual dependence of learning approaches $[19,20]$. In the present study, approaches to learning were determined in the context of studying in a clinical department. The original instrument comprised 42 items (six subscales) rated on a five-point Likert scale, with a value of five indicating that the statement was "always or almost always true of me" and one indicating that the statement was "never or only rarely true of me". To apply the questionnaire to medical education, Hilliard [12] removed 18 items containing general or abstract statements that might interfere with the "specific" content sought in the medical education setting. The present study used items similar to those in Hilliard's study. However, because of the clinical setting, 24 items in the Hilliard questionnaire were reworded to reflect the clinical teaching context. For example, item 4 in the original version ("I think browsing around is a waste of time, so I only study seriously what's given out in class or in the course outlines") was reworded to "I think that trying to be involved in all clinical activities is a waste of time, so I devote my effort to areas clearly identified in the objectives of this clerkship". In some cases the adjustment was slight, with only the context being changed. For example, item 20 ("I usually become increasingly absorbed in my work the more I do") was changed to "The more I am involved in clinical activities, the more absorbed I become in my work" [see Additional file 1].

\section{Statistical analysis}

Descriptive statistics were used for the participants' characteristics. Factor analysis using principal component analysis with oblimin rotation and internal consistency methods was conducted to examine the construct validity and the reliability of the scales. Correlation analysis among subscales and repeated measures analysis of variance were used for statistical comparisons. SPSS (17.0) software [21] was used for data analysis, and a statistically significant difference between means was set at the 0.05 level.

\section{Ethics}

Ethical clearance was received from the Ethics Committee for Biomedical Research Involving Human Subjects, the Universitas Gadjah Mada, Yogyakarta. No funding was sought for the study.

\section{Results and discussion}

Of 255 students, 209 returned the questionnaire (response rate $82.0 \%)$. Of these, 95 students were in their fifth year, and 114 were in their sixth year. Almost twice as many were female (134) as male (75). Most were not married (183). One-half (107) were housed in dormitories or home stays, about one-third (76) lived with parents and a small proportion lived with other relatives (17) or alone (9). It is typical for out-of-town students to live with relatives, in dormitories or in home stays.

The means and standard deviations for the subscales of students' approaches to learning and estimates of internal consistency are presented in Table 2. The scores for the deep learning approach were higher than those for the surface or achieving approach. Preclinical students in medical school are considered to have to be very competitive, high achievers to obtain high marks in examinations that test a wide range of factual knowledge. However, once a student has passed the early part of the course, success in the clinical part is assumed. Student comments during focus group discussions suggested that they are less competitive in their clinical years than during the earlier, more theoretical part of the course. Hilliard found that senior students were more interested in learning for the sake of learning and in acquiring the skills of a competent physician [12]. Furthermore, in the departments involved in the present

Table 2 Mean scores on the subscales of approaches to learning

\begin{tabular}{llll}
\hline Approach/scale/item & Mean & SD & Cronbach's alpha \\
\hline Surface approach & $\mathbf{2 1 . 6 1}$ & $\mathbf{5 . 2 3}$ & 0.74 \\
\hline Surface motive & 11.46 & 2.19 & 0.65 \\
\hline Surface strategy & 10.73 & 2.23 & 0.65 \\
\hline Deep approach & $\mathbf{2 7 . 4 9}$ & $\mathbf{5 . 9 8}$ & 0.83 \\
\hline Deep motive & 14.13 & 2.18 & 0.78 \\
\hline Deep strategy & 13.94 & 2.12 & 0.79 \\
\hline Achieving approach & $\mathbf{2 6 . 3 0}$ & $\mathbf{6 . 0 2}$ & 0.84 \\
\hline Achieving motive & 12.88 & 2.57 & 0.73 \\
\hline Achieving strategy & 14.01 & 2.36 & 0.81 \\
\hline
\end{tabular}


Table 3 Factors resulting from the factor analysis of approaches to learning subscales

\begin{tabular}{lll}
\hline Subscale & Factor $\mathbf{1}$ & Factor $\mathbf{2}$ \\
\hline Surface Motive & 0.11 & $\mathbf{0 . 8 4}$ \\
\hline Surface Strategy & 0.17 & $\mathbf{0 . 7 6}$ \\
\hline Deep Motive & $\mathbf{0 . 8 5}$ & 0.16 \\
\hline Deep Strategy & $\mathbf{0 . 8 8}$ & 0.12 \\
\hline Achieving Motive & 0.53 & $\mathbf{0 . 6 1}$ \\
\hline Achieving Strategy & $\mathbf{0 . 8 5}$ & 0.30 \\
\hline
\end{tabular}

study, assessments tend to require explanation and comprehension (oral examinations, case presentations and written assignments) and not merely memory recall. This practice may require students to use more deep learning.

Several studies of medical students in their non-clinical years have used either the Biggs SPQ instrument to measure surface, deep and achieving learning approaches, or the Entwistle-Ramsden Lancaster Approaches to Studying Inventory to measure reproducing, meaning and achieving orientations to learning $[4,22,23]$. The scoring methods used, numbers of items and medical school classes differed between these studies. All studies except Martenson's found deep or meaning scores to be the highest [23]. The Martenson study, conducted in a traditional medical school, reported surface scores as the highest.

The overall alpha value and the alpha value for each scale indicated a high level of internal consistency $(0.91)$ comparable with that in other studies $[7,10,12,24,25]$. In the present study, there were only four items per subscale. This could have been the reason for the higher alpha reliability (range $0.65-0.84)$ compared with the range $(0.60-$ 0.75 ) reported in studies with seven items per subscale [9]. Compared with a similar questionnaire applied in medicine, the alpha reliability was higher $(0.57-0.67$ in Hilliard [12]). Factors that may have influenced the higher reliability in this study were number of items (this study used the shorter version) and homogeneity of the students (age, marital status, and living arrangement) who completed the questionnaire. These results validate use of the modified questionnaire for assessing approaches to learning in a clinical setting. Further studies with larger samples are recommended to investigate the applicability of the questionnaire in other clinical settings.

To evaluate the construct validity of the questionnaire, the six subscale scores were subjected to principal component factor analysis followed by an oblimin rotation to a simple structure. Eigenvalues greater than 1.0 were adopted as a criterion for determining the number of factors to be extracted. Two factors with eigenvalues above 1.0 , which accounted for $67.7 \%$ of the variance, were obtained and are shown in Table 3. Examination of the screen test supported the two-factor solution.

On the basis of Biggs's original theory, there should be a three-factor solution identifying three learning approaches: deep, surface and achieving. However, subsequent research [9] suggested that there are only two solutions, deep and surface. The achieving subscales were usually found to either load on one of the other two factors or be divided between them. In 2001, Biggs and colleagues verified the revision of the SPQ with a two-factor structure [10]. The revised instrument assesses deep and surface approaches only and uses fewer (20) items. The present study also supports a two-factor solution, with the "achieving strategy" loaded on factor 1 (deep approach) and the "achieving motive" loaded on factor 2 (surface approach). These two factors explain $45.1 \%$ and $22.5 \%$, respectively, of the variance. Further discussion therefore considers only the deep and surface approaches to learning.

The relationships between the two scales and their subscales are shown in Table 4. There was a positive correlation $(.845 ; .887$; and .872$)$ between the deep approach and its three subscales and also between the surface approach and its subscales (.765; .719; and .756). The correlations were significant at the 0.01 or 0.05 level. Weak correlations between approaches and subscales show that the two approaches were dissimilar.

A surface approach will work if a student is trying to memorize information for reproduction [1]. However, excessive use of the surface approach can lead to missing

Table 4 Correlation between approaches to learning scales (coefficient correlations)

\begin{tabular}{|c|c|c|c|c|c|c|c|c|}
\hline Scales & SA & SM & SS & AM & DA & DM & DS & AS \\
\hline Surface approach/SA & 1.00 & & & & & & & \\
\hline Surface motive/SM & $0.765^{* *}$ & 1.00 & & & & & & \\
\hline Surface strategy/SS & $0.719^{* *}$ & $0.390^{* *}$ & 1.00 & & & & & \\
\hline Achieving motive/AM & $0.756^{* *}$ & $0.363^{* *}$ & $0.261^{* *}$ & 1.00 & & & & \\
\hline Deep approach/DA & $0.343^{* *}$ & 0.129 & $0.181^{* *}$ & $0.430^{* *}$ & 1.00 & & & \\
\hline Deep motive/DM & $0.279^{* *}$ & 0.069 & $0.136^{*}$ & $0.390^{* *}$ & $0.845^{* *}$ & 1.00 & & \\
\hline Deep strategy/DS & $0.243^{* *}$ & 0.056 & 0.134 & $0.330^{* *}$ & $0.887^{* *}$ & $0.644^{* *}$ & 1.00 & \\
\hline Achiev. strategy/AS & $0.363^{* *}$ & $0.203^{* *}$ & $0.196^{* *}$ & $0.396^{*}$ & $0.872^{* *}$ & $0.567^{* *}$ & $0.680^{* *}$ & 1.00 \\
\hline
\end{tabular}

**Correlation is significant at the 0.01 level (two-tailed).

${ }^{*}$ Correlation is significant at the 0.05 level (two-tailed). 
Table 5 Comparison between approaches to learning scores in three medical departments

\begin{tabular}{lccrr}
\hline Scales & Internal Med Mean (SD) & Surgery Mean (SD) & Neurology Mean (SD) & F, (df), p, eta $^{\mathbf{2}}$ \\
\hline Surface Approach & $36.14(5.35)$ & $34.81(6.08)$ & $35.05(4.14)$ & $.39(2,39) .55 .02$ \\
\hline Surface Motive & $11.90(2.19)$ & $11.29(2.61)$ & $11.67(1.76)$ & $.42(2,39) .86 .02$ \\
\hline Surface Strategy & $11.28(2.07)$ & $10.62(2.50)$ & $11.09(1.64)$ & $.50(2,39) .61 .03$ \\
\hline Achieving Motive & $12.95(2.56)$ & $12.90(3.10)$ & $12.28(2.10)$ & $.45(2,39) .64 .02$ \\
\hline Deep Approach & $42.71(4.83)$ & $42.92(5.59)$ & $40.81(4.91)$ & $1.18(2,39) .32 .06$ \\
\hline Deep Motive & $14.33(1.96)$ & $14.19(2.27)$ & $14.00(1.76)$ & $.15(2,39) .86 .01$ \\
\hline Deep Strategy & $14.48(1.78)$ & $14.43(1.94)$ & $13.48(1.86)$ & $1.90(2,39) .16 .09$ \\
\hline Achiev. Strategy & $13.90(2.07)$ & $14.33(2.67)$ & $13.33(2.48)$ & $.94(2,39) .40 .05$ \\
\hline
\end{tabular}

interconnections between elements, or the meanings and implications of what is learned. Students who use a surface approach tend to have an external locus of control (e.g. are highly oriented toward grades), study less and target their study toward material they believe will be included in the examination. Students who are less oriented toward grades have a deep approach to learning and study material in a broader sense.

The students' approaches to learning did not change significantly as they rotated through the three departments involved in this study. Table 5 presents the repeated measures analysis of variance results.

The small differences in students' approaches in this study suggest that contextual or environmental variables as well as individual perceptions of these variables influence students' use of deep or surface approaches to learning tasks. The lack of significant results in the longitudinal study is possibly attributable to the small sample used $(n=39)$ or the short period of time between measurements (six weeks for neurology and 12 weeks for internal medicine and surgery).

Despite there being no significant differences, the pattern of fluctuating surface and deep approach scores across different departments supports the idea that students have individual combinations of approaches when facing different tasks in the departments. These have been called study "orchestrations" by Meyer [26] and imply that students use strategies flexibly, according to which is most appropriate to the learning environment. In the present study, students had higher deep approach scores in all three departments, which may be explained by their being senior, clinical students. Lindblom-Ylanne and Lonka [27] suggested that an increasingly high degree of deep-level learning is needed toward the end of medical studies, and indeed found that this occurred in their study.

\section{Conclusion}

The findings of this study indicate that the internal consistency and factorial validity of the SPQ are comparable with those reported previously. Therefore, the questionnaire can be used with confidence to assess learning and study processes in the clinical context as well as across different learning cultures and educational systems. Further psychometric and validation studies are needed to enhance the usefulness of this instrument in educational and psychological research. The clinical students in this study had higher scores for deep learning. Being relatively close to graduation may have made them serious about learning and keen to acquire the skills of a competent physician. The longitudinal study fails to provide significant evidence that approaches to learning change according to rotation placement. Factors that might influence these results could be of interest in further studies.

\section{Additional file}

Additional file 1: Approaches to Learning Questionnaire. The questionnaire used in this study, which was based on previous work by Biggs et al. [10] and Hillard [12].

\section{Competing interests}

The author declares that they have no competing interests.

\section{Authors' contributions}

All authors participated in designing the study as initiated by $O E$, who managed all practical parts of the study and drafted the manuscript. LB and AR participated in finalizing the manuscript. All authors read and approved the final manuscript.

\section{Author details}

${ }^{1}$ Faculty of Medicine, Universitas Gadjah Mada, Jl. Farmako, Sekip Utara, Yogyakarta, Indonesia. ${ }^{2}$ School of Public Health and Community Medicine, UNSW, Sydney, Australia.

Received: 7 May 2012 Accepted: 7 November 2012

Published: 15 November 2012

\section{References}

1. Biggs JB: What do inventories of students' learning processes really measure? A theoretical view and clarification. Br J Educ Psychol 1993, 63:3-19.

2. Entwistle NJ, Hanley M, Hounsell D: Identifying distinctive approaches to studying. High Educ 1979, 8:365-380.

3. Schmeck RR, Ribich F, Ramanaiah N: Development of a self-report inventory for assessing differences in learning processes. Appl Psychol Meas 1977, 1:423-431.

4. Emilia O, Mulholland $\mathrm{H}$ : Approaches to learning of students in an Indonesian medical school. Med Educ 1991, 25:462-470. 
5. Biggs JB: From theory to practice: a cognitive systems approach. Keynote paper presented at the Annual Conference of the Higher Education Research and Development of the Australasia. Australia: Monash University; 1992.

6. Niles FS: Cultural differences in learning motivation and learning strategies: a comparison of overseas and Australian students at an Australian University. Int J of Intercultural Relat 1995, 19:369-385.

7. Zhang LF: University students' learning approaches in three cultures: in investigation of Biggs' 3P model. J Psychol 2000, 134(1):37-55.

8. O'Neil MJ, Child D: Biggs' SPQ: a British study of its internal structure. Br J Educ Psychol 1984, 54:228-234.

9. Kember D, Leung DYP: The dimensionality of approaches to learning: an investigation with confirmatory factor analysis on the structure of the SPQ and LPQ. Br J Educ Psychol 1998, 68:395-407.

10. Biggs JB, Kember D, Leung DYP: The revised two-factor Study Process Questionnaire: R-SPQ-2F. Br J Educ Psychol 2001, 71:133-149.

11. Abraham RR, Kamath A, Upadhya S, Ramnarayan K: Learning approaches to physiology of undergraduates in an Indian medical school. Med Educ 2006, 40:916-923.

12. Hilliard Rl: How do medical students learn: medical student learning styles and factors that affect these learning styles. Teach Learn Med 1995, 7(4):201-210.

13. MCManus IC, Richards P, Winder BC, Sproston KA: Clinical experience, performance in final examinations and learning style in medical students: prospective study. BMJ 1998, 31:345-350.

14. Stienborg M, Bandaranayake $C$ : Medical students' approaches to studying. Med Teacher 1996, 18(3):229-236.

15. Elllis RA, Goodyear P, Brilliant M, Prosser M: Student experiences of problem-based learning in pharmacy: conceptions of learning, approaches to learning and the integration of face-to-face and on-line activities. Adv Health Sci Educ 2008, 13:675-692.

16. Richardson JTE: Researching student learning: approaches to studying in campus-based and distance education. Buckingham: Open University Press; 2000.

17. de Jong JA S, Wierstra RFA, Hermanussen J: An exploration of the relationship between academic and experiential learning approaches in vocational education. Br J Educ Psychol 2006, 76:155-169.

18. Al Kadri HMF, Al-Moamary MS, Elzubair M, Magzoub ME, AlMutairi A, Roberts C, van der Vleuten C: Exploring factors affecting undergraduate medical students' study strategies in the clinical years: a qualitative study. Adv Health Sci Educ 2011, 16:553-567.

19. Birenbaum M: Assessment preferences and their relationship to learning strategies and orientation. High Educ 1997, 33:71-84.

20. Kember D, Jamieson QW, Pomfret M, Wong ETT: Learning approaches, study time and academic performance. High Educ 1995, 29:329-343.

21. SPSS Inc: SPSS 17.0 for Windows. Chicago:; 2008.

22. Newble DI, Gordon Ml: The learning style of medical students. Med Educ 1985, 19:3-8.

23. Martenson DF: Students' approaches to studying in four medical schools. Med Educ 1986, 20:532-534.

24. Fox RA, McManus IC, Winder BC: The shortened Study Process Questionnaire: an investigation of its structure and longitudinal stability using confirmatory factor analysis. Br J Educ Psychol 2001, 71:511-530.

25. Zeegers P: Approaches to learning in science: a longitudinal study. Br J Educ Psychol 2001, 71:115-132.

26. Meyer JHF: Study orchestration: the manifestation, interpretation and consequences of contextualised approaches to studying. High Educ 1991, 22:297-316.

27. Lindbloom-Ylane S, Lonka K: Individual ways of interacting with the Learning environment - are they related to study success? Learn Instr 1999, 9:1-18.

doi:10.1186/1472-6920-12-114

Cite this article as: Emilia et al:: Measuring students' approaches to learning in different clinical rotations. BMC Medical Education 2012 12:114.

\section{Submit your next manuscript to BioMed Central and take full advantage of:}

- Convenient online submission

- Thorough peer review

- No space constraints or color figure charges

- Immediate publication on acceptance

- Inclusion in PubMed, CAS, Scopus and Google Scholar

- Research which is freely available for redistribution
C Biomed Central 